\title{
Layered Teaching Method of English in Vocational Colleges
}

\author{
Shan $\mathrm{Gu}^{1, \mathrm{a}^{*}}$ \\ ${ }^{1}$ Fundamental Teaching Department, Tianjin Vocational College of Bioengineering, Tianjin, 300462, \\ China \\ gushan1981@126.com
}

\begin{abstract}
Keywords: Constructivist teaching English; English teaching; Teaching implicit stratification.
\end{abstract}
\begin{abstract}
With enrollment in higher vocational colleges, the average English level of the students significantly lower level jagged and traditional unified teaching objectives, teaching methods, teaching evaluation cannot effectively promote students of English to improve their English proficiency. Therefore, the teachers began to explore a variety of new teaching model, which many teachers advocate hierarchical teaching. But this so-called "dominant stratification teaching mode" embodiment larger, complex operation, needs the support of the school, a teacher's personal power alone cannot do. Meanwhile, in the course of implementation also found some drawbacks. So I tried on this basis a new kind of hierarchical teaching: "implicit hierarchical teaching mode" through the implementation of this pattern was found feasible and have a positive effect of teaching.
\end{abstract}

\section{Introduction}

In recent years, higher vocational education developed rapidly, increasing the size of enrollment [1]. Admission scores continue to reduce the overall level of the corresponding level on uneven ground, which is also reflected in the students' English proficiency. According to this truth, teachers are constantly changing and innovation in the teaching mode [2, 3]. "On Higher Vocational Education Teaching basic English requirements" proposed "for the current situation of higher vocational students enrolled uneven proposed uniform requirements, classification guidance" principle according to Department of Higher Education 2000 file vocational English teachers to try different teaching modes $[4,5]$. According to freshman English or SAT score organization newborn through a unified English exam, plus interviews or surveys of students, students were divided into different levels a, b, c, etc., consisting of different levels of classes, and then to different levels of students with different materials, different settings teaching objectives, the use of different teaching methods, using different teaching assessment methods [6-8]. That is the teaching content, objectives, methodology, assessment and other aspects of the hierarchical teaching. Throughout the process, teachers and students are clearly a student belongs to which level. This teaching model is called the article a "dominant hierarchical teaching mode."

This teaching model has a positive teaching effect, but there are also some problems, such as lack of education leads layered teachers, teacher becomes large, larger class type [9], the lower will be the students' psychological gap [10] . In addition, due to various reasons and teaching leadership reluctant to implement large-scale stratified teaching. Therefore, according to this situation, I order to play to their strengths hierarchical teaching, try a "hidden hierarchical teaching mode."

\section{"Implicit Hierarchical Teaching Mode" Discussion and Practice}

The so-called "hidden hierarchical teaching model" is based on the student teacher's college entrance examination scores, student surveys, interviews the students hidden layers, namely teachers clearly belongs to which each student level: honors, secondary students, Poor Students. But will not be separate teaching according to their level of hierarchy. But use the same teaching materials for different levels of students presented different levels of tasks, requirements, using different teaching methods and different evaluation criteria, in order to achieve all the students in the learning process and progress have a harvest, and finally try to make Vocational students' English for all students to reach the goal of reunification. The following article will be in English teaching theory as a guide on 
how to implement "hidden leveling teaching" in teaching practice, to develop students' English proficiency (Fig. 1).

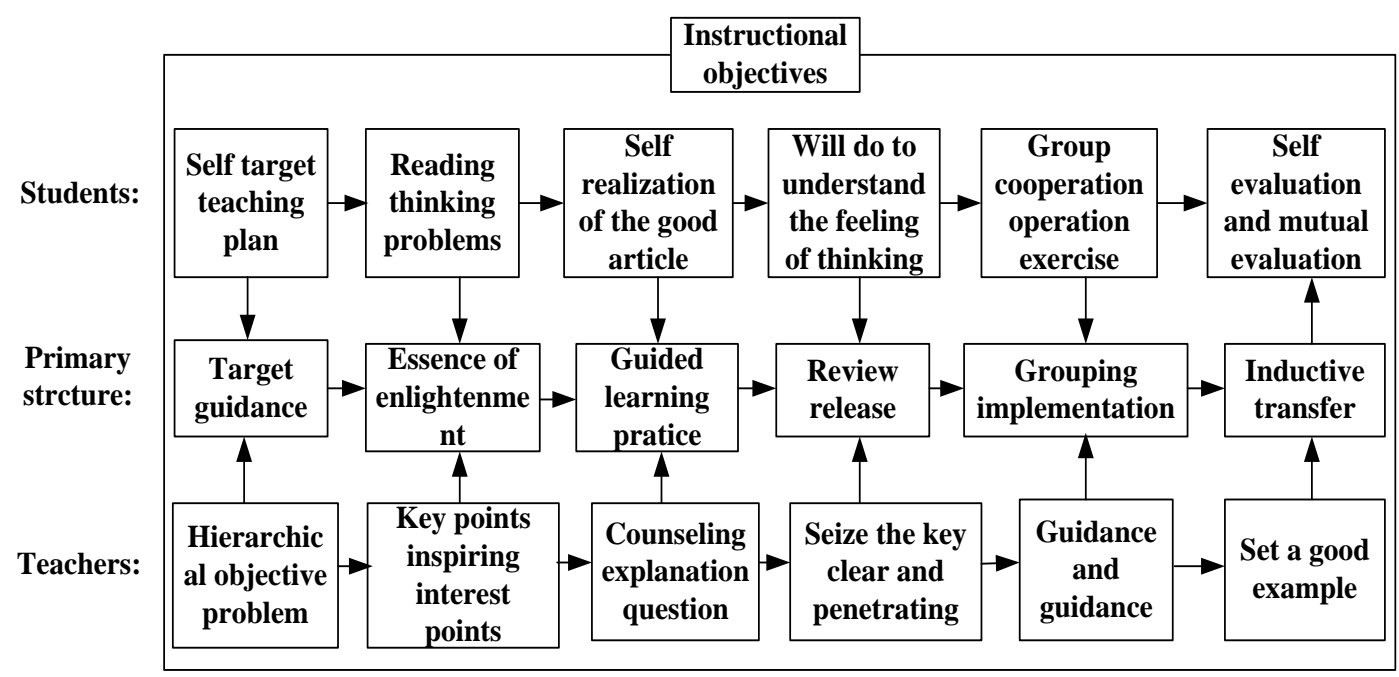

Figure 1. Students' English proficiency

The late 1970s and early 1980s the famous American linguist Krashen proposes a more complete second language acquisition theory. Enter his theories about language learning for foreign language teaching it provides a good theoretical framework. Krashen believes that only when learners come into contact with "comprehensible input" that is slightly higher than his current level of second language input, and he can focus on the meaning of information or understanding when not on the form of understanding, in order to produce learned. Krashen $i+1$ input theory current levels " $i$ " on behalf of learners, "1" represents slightly more than the current level of language learners material. Through these efforts, the learner understands the language input "incomprehensible ingredients", resulting in the acquisition, progress.

"Individualized" teaching principles and teaching strategies for treating teaching in ancient China had already been presented in individual differences. Teaching today in talking about individualized, meaning basically the same with the ancient, mainly includes three aspects: (1) teachers to understand and grasp the students' personality, learning differences and learning ability and other aspects; (2) Teachers from the reality of the students, to teaching students of different situations for different organizations; (3) teachers in the teaching process to the needs of all students, so that the full development, learn a director.

The following "hidden hierarchical teaching mode" teaching practice is mainly based on two or more theoretical basis, so that different levels of students in the learning process in the harvest, progress, a sense of accomplishment.

\section{Teaching Practice}

For a college freshman, mainly carried out based on the student's college entrance examination scores stratified English: honors, secondary students and poor students. In addition this, but also through the questionnaire, the students conduct interviews, observe student performance in the classroom and other ways for students to conduct a comprehensive understanding. Learn English if students interested in English capacity strengths and weaknesses, and whether students had wanted to have the confidence to improve their English skills, most want to improve their English skills which aspects and so on. So easy to stimulate students in the teaching process, in order to improve and adjust the level of the students.

Vocational students do not know how some self-word, a few even how to pronounce the word not. In order to better grasp the words and the students to help them clear the text to read and appreciate the obstacles before the texts were focused on teaching the word. But the degree of good students, the 
lesson seems somewhat redundant. Therefore, in the process carried out on this lesson implicit stratification is necessary. Poor Students can only ask pronunciation, meaning know Chinese, and to find the text contains the word sentences; secondary students claim will read, understand English interpretation, and to find the message contains the word sentences, and sentences with the word as much as possible; honors in addition to requirements secondary students must master other than the master, requiring them to be listed in English synonyms and compared.

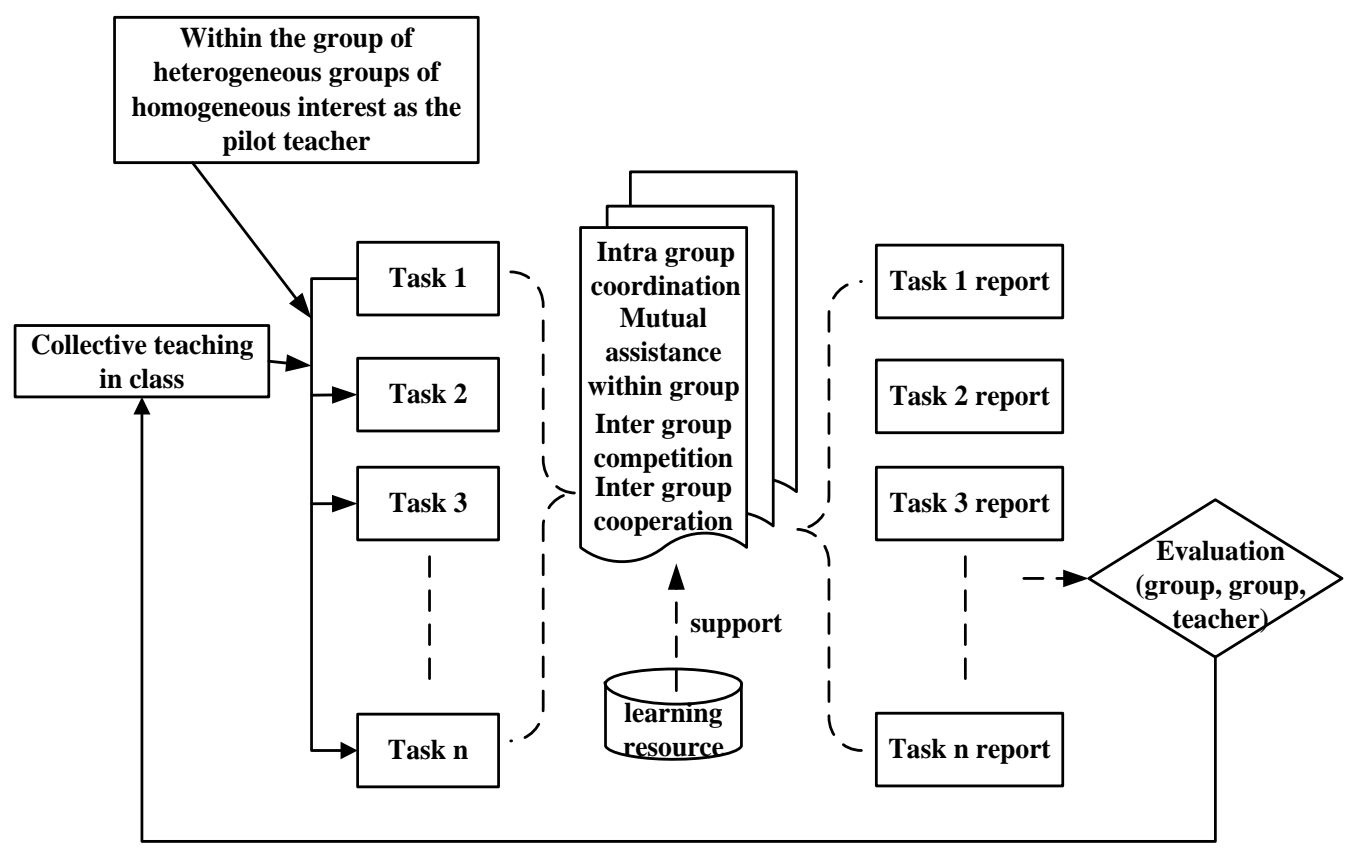

Figure 2. Teaching practice flow

Understand the chapter structure of the article. In the teaching process, we found that some students are often reading an article mainly about content not know what, this is mainly because the students are accustomed to attention words appear in the text, leaving the reading language fragment fragmentation. Hidden hierarchical teaching students can find below the middle of the text can be summarized in the various parts of the sentence (most articles in English with the subject sentence), above average students in their own language we summarize the main content of each section.

"Recessive leveling teaching" requirements for students at different levels are different. Students are encouraged to below the middle of them read the original text answer questions; and for above-average students to encourage them to use their own language to answer questions. In addition, teachers in preparing lessons for the design must be easy to have a problem difficult cross appeared the easier issues left to lower level students. Such words can make all the students can participate in the classes. In addition, each article has focused on sentences and beautiful sentences require students to understand the basis to be able to enjoy them. For these sentences, "hidden leveling teaching" requirements for students at different levels are different.

The exercise is to explain the British teaching more boring part. But it is also an essential part of a process because it is a consolidation of texts and test how well the mastery of knowledge. Here in one of these exercises - A Case Study of translation problems. "Recessive leveling teaching" in teaching poor students try to find the requested sentence for each word corresponding to the English word; secondary students to be able to find the corresponding word and sentence composition; honors to be able to find the Chinese translation of sentences different methods, namely a plurality of corresponding English sentence. Layered teach content flowchart was shown in Fig. 3. 


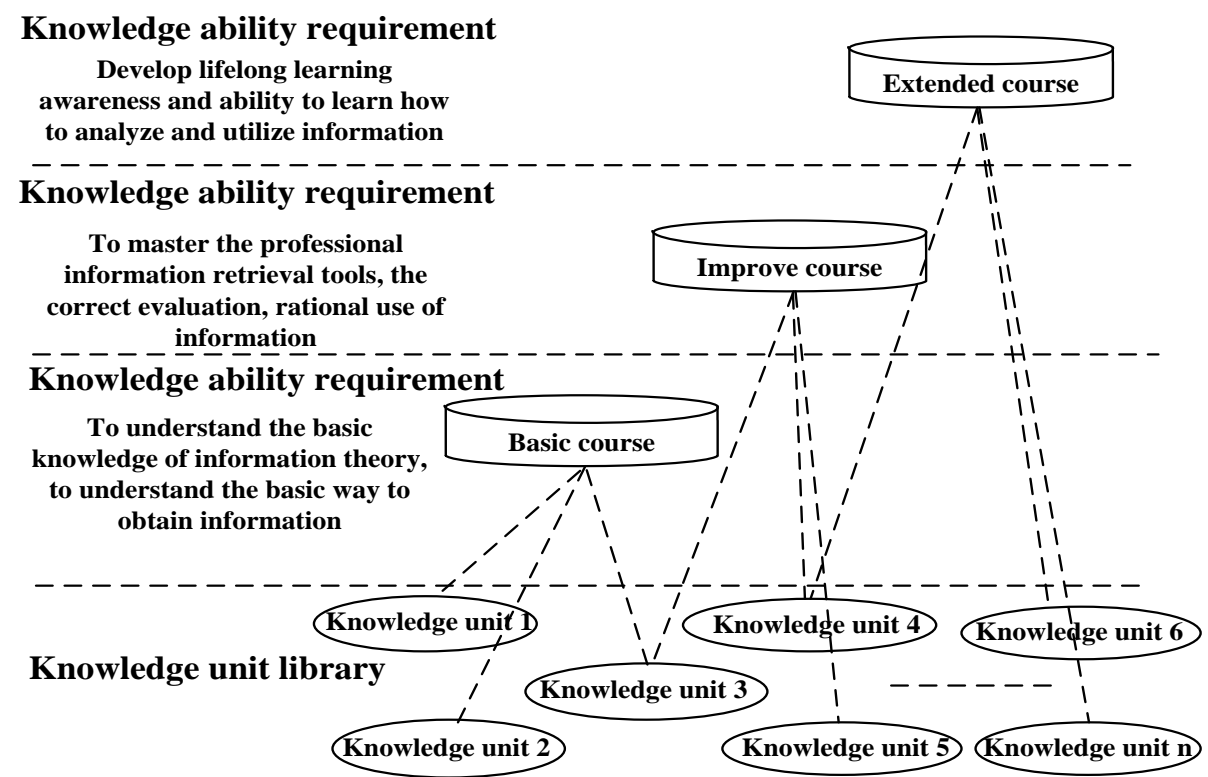

Figure 3. Layered teach content flowchart

English teaching process in the evaluation of students are mainly two: formative assessment and summative assessment. For the "hidden leveling teaching", formative assessment is the main assessment methods. At the same time for different levels of students cannot use the same criteria to evaluate, to have different assessment criteria, stratified evaluated. The general principle is based on the students themselves as the reference: whether a more proactive attitude towards learning, study whether more effort, to learn whether there is progress, whether improved English skills and so on. Of course, in addition to the formative assessment, summative assessment should be part of the total assessment, as a performance test is comprehensive ability of students.

\section{Conclusions}

According to the teaching practice, Krashen $i+1$ input Vocational English "hidden hierarchical teaching mode" theory and individualized teaching theoretical guidance has a positive effect:

(A) Good classroom atmosphere, about Ninety-five percent of the students are actively involved in classroom learning.

(B) Students learn fun, learn less pressure. If eugenics and poor students the same requirements, the same target, the level of poor students feel powerless, and cannot, learning more and more pressure. Teaching at making them relief, see hope.

(C) Students have self-confidence, learning more and more interested. Each student feels progress, the teacher affirmed.

(D) Teacher-student rapport. The students no longer feel eccentric teacher, just like the students with good results. Because the teacher always concerned about every student, I hope every student has made progress.

In short, the "hidden hierarchical teaching mode" so that students feel that there is progress, there is a sense of accomplishment, but also to avoid the "dominant hierarchical teaching" in the lower-level students psychological gap. More importantly, as long as the individual efforts of teachers will be able to implement and does not require the approval of the leadership of teaching and school complex.

\section{References}

[1] Uzum B. uncovering the layers of foreign language teacher socialization: A qualitative case study of Fulbright language teaching assistants [J]. Language Teaching Research, 2015: 
1362168815614338.

[2] Juan Z. On Translating Chinese Internet Buzzwords into English from the Perspective of Scoops Theory: Taking the Example of 2012 Chinese Internet Buzzwords [J]. Journal of Hubei Engineering University, 2013, 2: 017.

[3] Chen H. Research on Literary Translation Capability and the Construction of Training Mode[C]//2015 International Conference on Education Technology and Economic Management. Atlantis Press, 2015.

[4] Ajayi L. High school teachers' perspectives on the English language arts Common Core State Standards: an exploratory study [J]. Educational Research for Policy and Practice, 2016, 15(1): $1-25$.

[5] Zhang Z. Chinese and Canadian teachers implement a hybrid Sino-Canadian curriculum: A multiliteracies perspective [J]. Teaching and Teacher Education, 2015, 48: 106-116.

[6] Underwood P R. Teacher beliefs and intentions regarding the instruction of English grammar under national curriculum reforms: A Theory of Planned Behaviors perspective $[\mathrm{J}]$. Teaching and Teacher education, 2012, 28(6): 911-925.

[7] ZHOU Y, WANG Y. Theoretical basis and strategy selections for the English translation of traditional Chinese medical terms from 1981 to 2010[J]. China Journal of Traditional Chinese Medicine and Pharmacy, 2013, 4: 042.

[8] Al-Issa A S M. Making a Case for New Directions in English Language Teaching Research at an Omani University: A Critical Qualitative Content Analysis Report [J]. The Qualitative Report, 2015, 20(5): 560 .

[9] Liu D, Li L. Analysis of the science development of the PST-CCE in applied undergraduate colleges and universities [J]. 2015.

[10]Celik S. Internet-assisted technologies for English language teaching in Turkish universities [J]. Computer Assisted Language Learning, 2013, 26(5): 468-483. 